\title{
MUSCLE OXYGENATION DURING EXERCISE IN PHYSICALLY ACTIVE AND OVERWEIGHT 6-19-YEAR-OLD CHILDREN
}

\author{
Vaida Šidlauskaitė, Birutė Zacharienė, Arvydas Stasiulis \\ Lithuanian Sports University, Kaunas, Lithuania
}

\begin{abstract}
Background. The purpose of our study was to compare muscle oxygenation during walking exercise in physically active, non-physically active normal weight and overweight 6-19- year-old children.

Methods. Twenty four normal weight, physically non-active (NPA), 27 normal weight physically active (PA) and 17 overweight (OW) 6-19-year-old children participated in this study. Muscle oxygenation was recorded by near infrared spectroscopy during constant $(6 \mathrm{~min}, 6 \mathrm{~km} / \mathrm{h}, 4 \%$ grade) and increasing walking exercise (modified Balke test). Heart rate was recorded using Polar system.

Results. Overweight children of all age groups demonstrated slower time constant of muscle oxygenation during constant walking exercise (37.2 \pm 3 (6-10-year-old); $29.7 \pm 2$ (11-15-yr old), $33.4 \pm 5.1$ (16-19-year-old)) and lower threshold of oxygenation (TO) $(84.3 \pm 10.1,104.5 \pm 17.1,188.5 \pm 69.4$ respectively) during increasing walking exercise as compared NPA (111.8 $\pm 13.7,124.4 \pm 29.8,192.6 \pm 84$ respectively $)$ and PA (106.2 $\pm 35.2 ; 122 \pm 13.3$; $340.8 \pm 44.2$ respectively) peers. The time constant of Deoxy-Hb during constant walking exercise was the shortest in PA $(16.7 \pm 2.3,16.9 \pm 2,15.5 \pm 4.7$ respectively $)$ in all age groups. The TO was higher in PA as compared to NW only in 16-19 years of age.

Conclusion. Muscle oxygenation during constant or increasing exercise is dependent on both body weight and physical activity status in 6-19-year-old children.
\end{abstract}

Keywords: muscle oxygenation, children, physical activity, overweight.

\section{INDRODUCTION}

$\mathrm{M}$ ore favorable biological cardiovascular disease risk-factor, such as low blood pressure, has association with psychological health, such as higher levels of selfesteem, and lower levels of anxiety and stress have associations with physical activity in young age. In childhood, physicalactivitymaintainsan appropriate bone strength, and it contributes to normal skeletal development (Van der Hors, Paw, Twisk, \& Van Mechelen, 2007). Physical activity has positive influence on VO2 max and blood cholesterol (Dobbins, Husson, DeCorby, \& LaRocca, 2013). Children display a faster exponential rise in the phase II pVO2 kinetics, which can be the rise in muscle $\mathrm{O} 2$ consumption during different intensity exercises (Armstrong, Tomkinson, \& Ekelund, 2011). Fawkner, Armstrong, Potter, and Welsman (2002) reported faster $\mathrm{VO}_{2}$ kinetics in children than adults. Some studies showed no difference in kinetics (Hebestreit, Kriemler, Hughson, \& Bar-Or, 1998).

Even $49 \%$ of children are less physically active that 60 min per day nowadays (Harrison et al., 2017). Since physical activity is decreasing, overweight and obesity among adults and children are increasing. Pediatric obesity can harm multiple body systems: respiratory system, including pulmonary function, exercise intolerance, gas exchange, and airway musculature (Durbin et al., 2017). Maximum oxygen uptake $\left(\mathrm{V}_{2} \max \right)$ may 
not be achieved due to reduced motivation and peripheral fatigue among overweight and obese children (Dias et al., 2017). Ventilatory anaerobic threshold and maximal oxygen uptake related to body weight are lower in the obese than in normal weight 9-14-year-old children (Zanconato et al., 1989). The pulmonary oxygen uptake response is deleteriously influenced by obesity in prepubertal children (McNArry, Lambrick, Westrupp, \& Faulkner, 2015). Obese children demonstrate significantly slower $\mathrm{VO}_{2}$ kinetics compared to normal weight children during moderate- and heavy intensity exercise (Lambrick, Faulkner, Westrupp, \& McNarry 2013).

Near-infrared spectroscopy (NIRS) has been used to determinate the concentration of lightabsorbing chromophores (Ferreira, Hueber, \& Barstow, 2007). NIRS is a noninvasive and direct method to determine oxygenation in tissue (Van Beekvelt, Colier, Wevers, \& Van Engelen, 2001). Respiratory muscles deoxygenate during incremental exercise and ventilatory threshold can be determined by NIRS in children (Moalla, Dupont, Berthoin, \& Ahmaidi, 2005).

The mean time response for muscle tissue deoxygenation is significantly faster in children than adults at the onset of high intensity exercise (Willcokcs, Williams, Barker, Fulford, \& Armstrong, 2010). 13-17-year-old boys demonstrate significant changes in absolute hemoglobin concentrations and oxygenation in the exercising muscle during incremental cycling and post-exercise recovery (Ganesan et al., 2016). 9-year-old girls demonstrate an earlier change in $[\mathrm{HHb}]$ compared with same age boys during ramp incremental exercise (McNarry et al., 2015). Also, prepubertal, pubertal, postpubertal trained girls demonstrate a significant rightward shift in the sigmoidal response of [HHb] compared with untrained girls (McNarry et al., 2010). The muscle oxygenation and blood volume curves decreased immediately at the beginning of maximal voluntary isometric exercise among 12-year-old untrained children (Moalla, Merzouk, Costes, Tabka, \& Ahmaidi, 2006). Also, Vandekerckhove, Coomans, Moerman, De Wolf, and Boone (2016) assessed muscle oxygenation responses and found that they undergo significant changes as work rate increases at high intensity and are strongly interrelated and associated with changes in pulmonary gas exchange.
Training-induced adaptation in aerobic fitness and muscle oxygenation among adults is carefully analyzed, but findings in children still are not clear. Muscle oxygenation in separate children age groups during different exercise load were investigated. No research investigating muscle oxygenation in 6-19-year-old physically active and overweight children was found.

The purpose of our study was to compare muscle oxygenation during treadmill exercise in physically active, non-physically active normal weight and overweight 6-19-year-old children.

\section{METHODS}

Participants. Twenty-four normal weight, physically non-active (NPA) 6-19-year-old, 27 normal weight physically active (PA) 6-19-yearold and 17 overweight (OW) 6-19-year-old children participated in this study. OW status was established using age, height and weight. Written informed consent was obtained from the parents and written assent - from the participants. The children were screened using international physical activity questionnaire (IPAQ). The causes which eliminate participants from research were: heart disease, diabetes, epilepsy, musculoskeletal problems.

Ethical approval for the research was obtained from Kaunas regional Ethics Committee.

Measurements. Participants height was measured using stadiometer to the nearest $0.01 \mathrm{~m}$. Body mass was measured using body composition analyzer "TBF-300" (Japanese) to the nearest 0.1 $\mathrm{kg}$ beam. BMI was calculated body mass $(\mathrm{kg})$ dividing by height squared $\left(\mathrm{m}^{2}\right)$.

Heart rate (HR) was measured with "Polar" system.

Muscles oxygenation was measured using a tissue near infrared spectrometer (NIRS) (Standard System Model 325, Hutchinson Technology). The detector for recording of infrared signal was placed on the left leg (m. vastus lateralis). Before applying the probes, the skin under the probes was shaved if it was necessary. The NIRS detector was fixed to the leg with black rubber holders and adhesive tape to minimize incidental movement. The muscle oxygenation measurements (oxygenized, deoxygenized and total hemoglobin) were collected continuously every $3-5 \mathrm{~s}$ throughout the entire protocol. The sample rate was set to $1 \mathrm{~Hz}$. 
Table 1. Participants' characteristics

\begin{tabular}{|c|c|c|c|c|c|c|c|c|c|}
\hline \multirow[b]{2}{*}{ Years } & \multicolumn{3}{|c|}{ NPA } & \multicolumn{3}{|c|}{ PA } & \multicolumn{3}{|c|}{ OW } \\
\hline & 6-10 & $11-15$ & 16-19 & 6-10 & $11-15$ & 16-19 & 6-10 & 11-15 & $16-19$ \\
\hline Age (yr) & $\begin{array}{l}8.3 \pm \\
1.96\end{array}$ & $\begin{array}{l}11.16 \pm \\
0.4\end{array}$ & $\begin{array}{l}18.66 \pm \\
0.89\end{array}$ & $\begin{array}{l}9.37 \pm \\
1.14\end{array}$ & $\begin{array}{l}12 \pm \\
1\end{array}$ & $\begin{array}{l}19 \pm \\
1\end{array}$ & $\begin{array}{l}9 \pm \\
0.6\end{array}$ & $\begin{array}{l}13 \pm \\
0.71\end{array}$ & $\begin{array}{l}17.83 \pm \\
1.47\end{array}$ \\
\hline Heigh $(\mathrm{cm})$ & $\begin{array}{l}134.3 \pm \\
24.1\end{array}$ & $\begin{array}{l}150.83 \pm \\
2.79\end{array}$ & $\begin{array}{l}179.83 \pm \\
12.9\end{array}$ & $\begin{array}{l}142.25 \pm \\
10.57\end{array}$ & $\begin{array}{l}152.6 \pm \\
6.1\end{array}$ & $\begin{array}{l}184.66 \pm \\
4.32\end{array}$ & $\begin{array}{l}145.3 \pm \\
8.1\end{array}$ & $\begin{array}{l}164 \pm \\
5.48\end{array}$ & $\begin{array}{l}178.66 \pm \\
4.97\end{array}$ \\
\hline Weight (kg) & $\begin{array}{l}34.3 \pm \\
7.15\end{array}$ & $\begin{array}{l}41.86 \pm \\
5.06\end{array}$ & $\begin{array}{l}69.74 \pm \\
15.25\end{array}$ & $\begin{array}{l}37.39 \pm \\
7.02\end{array}$ & $\begin{array}{l}42.8 \pm \\
3.9\end{array}$ & $\begin{array}{l}76.33 \pm \\
7.12\end{array}$ & $\begin{array}{l}46.16 \pm \\
6.4\end{array}$ & $\begin{array}{l}72.4 \pm \\
7.54\end{array}$ & $\begin{array}{l}91.5 \pm \\
9.85\end{array}$ \\
\hline BMI $\left(\mathrm{kg} / \mathrm{m}^{2}\right)$ & $\begin{array}{l}18.94 \pm \\
1.2\end{array}$ & $\begin{array}{l}17.75 \pm \\
0.68\end{array}$ & $\begin{array}{l}21.5 \pm \\
1.02\end{array}$ & $\begin{array}{l}18.35 \pm \\
1.3\end{array}$ & $\begin{array}{l}18.5 \pm \\
1.56\end{array}$ & $\begin{array}{l}22.4 \pm \\
0.7\end{array}$ & $\begin{array}{l}26.1 \pm \\
1.44\end{array}$ & $\begin{array}{l}26.7 \pm \\
1.6\end{array}$ & $\begin{array}{l}28.7 \pm \\
1.25\end{array}$ \\
\hline
\end{tabular}

Constant walking exercise. It was $6 \mathrm{~min}$ walking at $6 \mathrm{~km} / \mathrm{h}$ speed and a $4 \%$ grade treadmill test. During each session $\mathrm{StO} 2$ data were collected at subject's rest and during walking (at $6 \mathrm{~km} / \mathrm{h}$ and a $4 \%$ grade treadmill) for 6 minutes. The testing protocol was then started as follows: $1 \mathrm{~min}$ baseline with participants standing on the treadmill; 3-min unloaded warm-up, participants slowly walked on treadmill (at $3 \mathrm{~km} / \mathrm{h}, 0 \%$ grade); brake for $1 \mathrm{~min}$ (treadmill lifts up till 4\% upgrade, speed increase till $6 \mathrm{~km} / \mathrm{h}$, participants were standing on the sides of treadmill); participants were walking $6 \mathrm{~min}$ (at $6 \mathrm{~km} / \mathrm{h}$ and $4 \%$ grade treadmill); participants were resting for $5 \mathrm{~min}$ in lying down position.

Increasing walking exercise. It was modified Balke test. Following a $1 \mathrm{~min}$ period of standing gas exchange, subjects began a step transition into a 3 -minute stage at $3 \mathrm{~km} / \mathrm{h}$ speed and $0 \%$ grade. The progressive protocol continued with a 4-min stage at $6 \mathrm{~km} / \mathrm{h}$ and grade of treadmill was increased to $2,4,6,8,10 \%$ and so far till subject can continue. Subjects were verbally encouraged to give maximal effort during the test until volitional exhaustion was achieved. $\mathrm{StO}_{2}$ data were collected at subjects during test and in resting.

Study design. Participants started the experimental procedure at least intense exercise for $24 \mathrm{~h}$ before testing. Participants had to come to laboratory 2 times.

Two consecutive walking exercises sessions (separated by $45 \mathrm{~min}$ ) were performed on the first arrival.

Increasing walking exercise - Balke - was performed the next week after consecutive walking exercise (the second arrival time). Participants were walking on the treadmill at $6 \mathrm{~km} / \mathrm{h}$ speed, every minute treadmill angle was raising up 2 degrees during high intensity test. Subjects continued walking till exhaustion.
Data analysis. The kinetics deoxygenized hemoglobin (Deoxy-Hb) was assessed applying monoexponential equation Deoxy-Hb $(\mathrm{t})=$ Deoxy$\mathrm{Hb}(\mathrm{b})+\mathrm{A}\left(1-\mathrm{e}^{-\mathrm{t} / \tau}\right)$, where Deoxy-Hb (t) is the Deoxy-Hb at any time point; Deoxy-Hb (b) is the baseline Deoxy-Hb at rest (standing); $\mathrm{A}$ is the amplitude of Deoxy-HB response, and $\left(1-\mathrm{e}^{-t / \tau}\right)$ is the exponential function describing the rate at which Deoxy-Hb is rising towards the amplitude. In the exponential function, $t$ is time; $\tau$ is the time constant.

Threshold of muscle oxygenation (TO) was calculated analysing relationship between Deoxy$\mathrm{Hb}$ and walking power during increasing walking exercise. The power at which Deoxy-Hb started to decrease was considered as TO.

Statistical analysis. All statistical analyses were performed using SPSS version 22.0. All values were expressed as mean \pm standard deviation. Comparison of threshold of oxygenation, muscle oxygenation time constant and HR were analyzed by nonparametric data analyze Mann - Whitney Test. Significance was accepted at $p<.05$.

\section{RESULTS}

Time constant kinetics of Deoxy-Hb during constant walking exercise was significantly different $(p<.05)$ among all age groups: $6-10$-year-old group PA $(16.7 \pm 2.3) \mathrm{NPA}(21.7 \pm 1.5)$, OW $(37.2 \pm$ $3.1)$; 11-15-year-old group PA (16.9 \pm 2$)$, NPA (20.2 \pm 1.3$)$, OW (29.7 \pm 2.8$), 16-19$-year-old group PA $(15.5 \pm 4.7)$, NPA $(19.9 \pm 2.3)$, OW $(33.4 \pm 5.1)$ (Figure 1).

TO during increasing walking exercise was significantly different between 6-10-year-old PA $(106.2 \pm 35.2)$ and OW (84.3 \pm 10.1$)$ groups and between NPA $(111.8 \pm 13.7)$ and OW $(84.3 \pm 10.1)$ groups $(p<.05)$, between $11-15$-year-old PA $(122 \pm$ 
13.3) and OW (104.5 \pm 17.1) groups and between NPA (124.4 \pm 29.8$)$ and OW (104.5 \pm 17.1$)$ groups $(p<.05)$, between 16-19-year-old PA (340.8 \pm 44.2) and OW (188.5 \pm 69.4) groups and PA $(340.8 \pm 44.2)$ and NPA $(192.6 \pm 84)$ groups $(p<$ $.05)$. There were no significant differences in TO between $6-10$-year-old PA $(106.2 \pm 35.2)$ and NPA $(111.8 \pm 13.7)$ groups, 11-15-year-old PA (122 \pm 13.3) and NPA (124.4 \pm 29.8$)$ and 16-19-year-old OW $(188.5 \pm 69.4)$ and NPA $(192.6 \pm 84)$ groups $(p>.05)$ (Figure 2).

Relative threshold of muscle oxygenation (RTO) during increasing walking exercise was significant different $(p<.05)$ between NPA $(3.25 \pm 0.7)$ and
OW (1.49 \pm 0.45$), \mathrm{PA}(2.84 \pm 0.56)$ and OW $(1.49 \pm$ $0.45)$ in 6-10-year-old group, between NPA (2.97 \pm $0.54)$ and $\mathrm{OW}(1.82 \pm 0.45)$, PA $(3.06 \pm 0.23)$ and OW (1.82 \pm 0.45$)$ in 11-15-year-old group, between NPA $(2.76 \pm 0.65)$ and OW $(2.06 \pm 0.43)$, PA $(4.46 \pm$ $0.75)$ and OW (2.06 \pm 0.43$)$, NPA $(2.76 \pm 0.65)$ and PA (4.46 \pm 0.75$)$ in 16-19-year-old group. There was no significant difference $(p>.05)$ between NPA $(3.25 \pm 0.7)$ and PA $(2.84 \pm 0.56)$ in $6-10$-year-old group, between NPA $(2.97 \pm 0.54)$ and PA $(3.06 \pm$ 0.23 ) in 11-15-year-old group (Figure 3).

Heart rates during increasing walking exercise in NPA, PA and OW groups were not significantly different $(p>.05)$ (Figure 4).
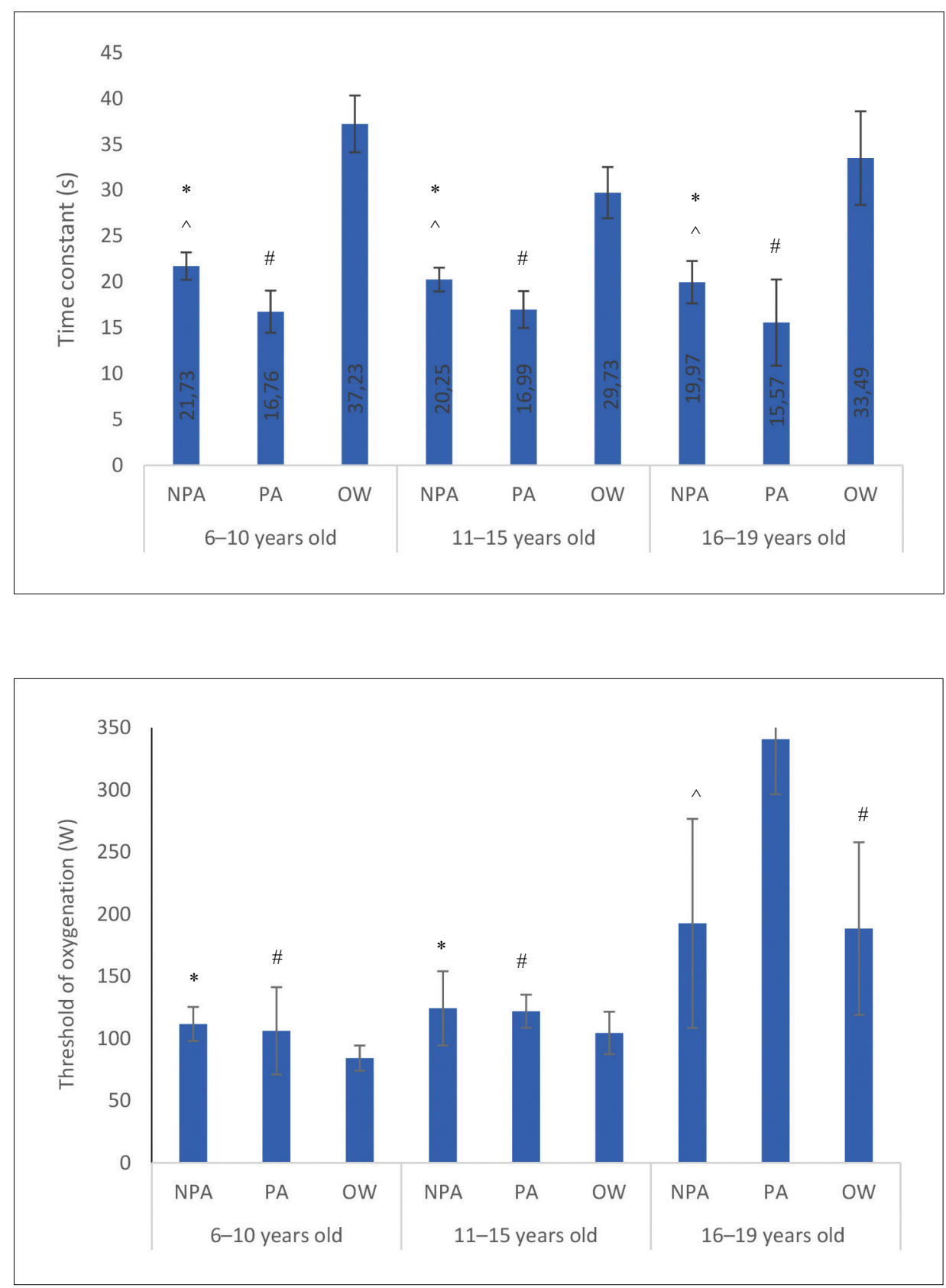

Figure 1. Time constant of muscle oxygenation kinetics during constant walking exercise in non-physically active (NPA), physically active (PA) and overweight (OW) 6-19-year-old children

Note. * significant difference between NPA and OW $(p<$ $.05)$, \# significant difference between PA and OW $(p<.05)$, $\wedge$ significant difference between NPA and PA $(p<.05)$.

Figure 2. Threshold of muscle oxygenation during increasing walking exercise in non-physically active (NPA), physically active (PA) and overweight (OW) 6-19-year-old children

Note. * significant difference between NPA and OW ( $p<$ $.05)$, \# significant difference between PA and OW $(p<.05)$, $\wedge$ significant difference between NPA and PA $(p<.05)$. 
Figure 3. Relative threshold of muscle oxygenation during increasing walking exercise among nonphysically active (NPA), physically active (PA) and overweight (OW) 6-19year-old children.

Note. * significant difference between NPA and OW $(p<$ $.05)$, \# significant difference between PA and OW $(p<$ $.05), \wedge$ significant difference between NPA and PA $(p<$ $.05)$.

Figure 4. Heart rates during increasing walking exercise in non-physically active (NPA), physically active (PA) and overweight (OW) 6-19-year-old children
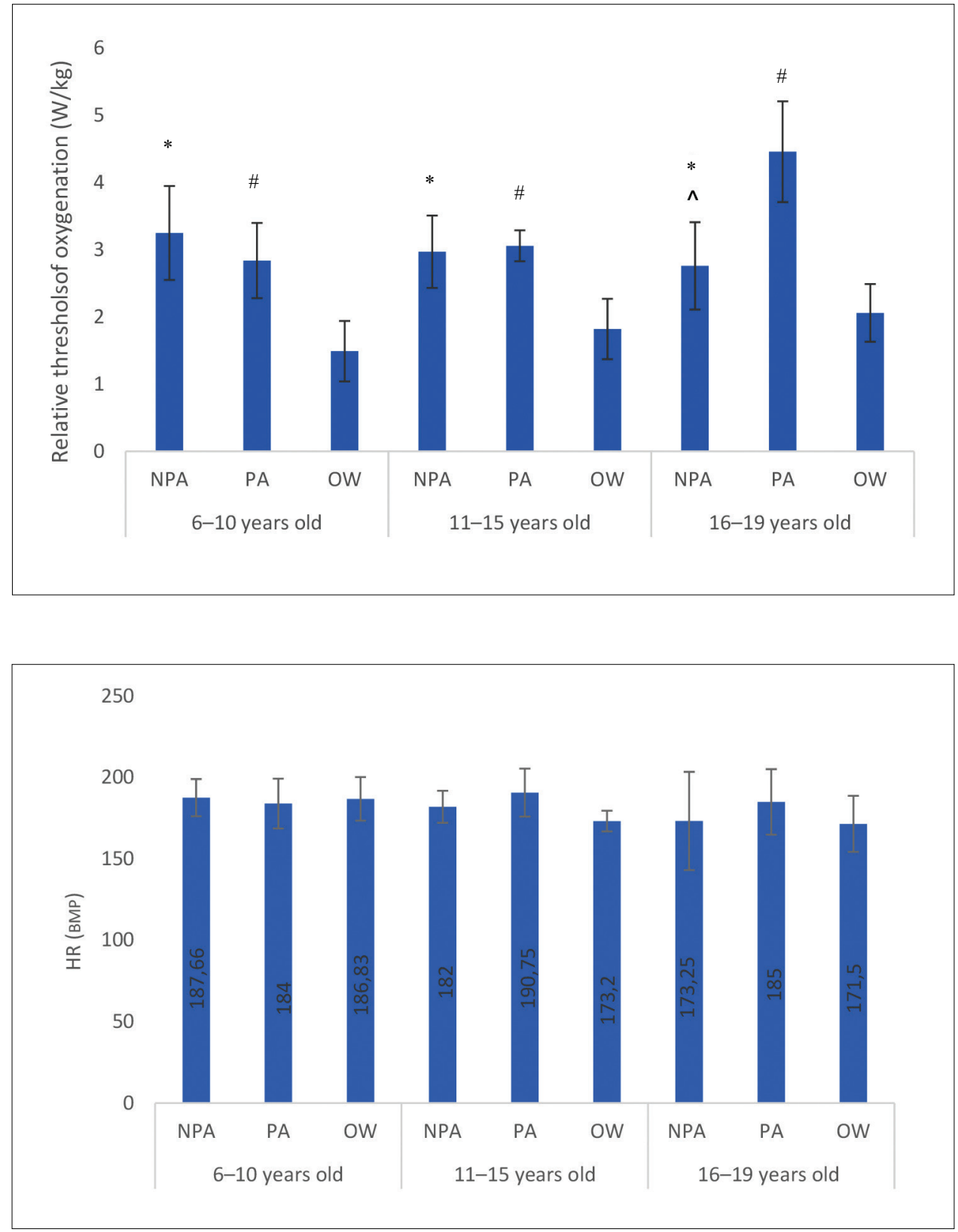

\section{DISCUSSION}

Our findings confirm slower muscle oxygenation and faster peripheral fatigue among overweight and non-physically active children of 6-19-year-olds compared with physically active children of the same age. Similar findings were detected by other researchers: Breese with coworkers (2010) found that high - intensity exercises have influence not only on slower phase II $\tau$ and a greater $\mathrm{pVO}_{2}$ slower component but also hypothesized about age dependent change in muscles and mitochondrial oxidation and differences in muscle fiber recruitment patterns. It is known that trained adults and children have more developed muscles. This leads to the bigger number of mitochondrias, therefore physically active children demonstrate slower peripheral fatigue compared with non-physically active children. Our findings demonstrate faster changes in [HHb] among 6-19-year-old physically active children compared with same age non-physically active children and overweight children.

Since the capacity of sustainable exercise depends on supplying the contrasting muscle with $\mathrm{O} 2$ in proportion to their metabolic requirements 
(Okushima et al., 2015), physically active children demonstrate better endurance compared with overweight or physically non-active children.

Our research involved children of various ages (6-19 years old), some results might be and are influenced by puberty. The peak $\mathrm{VO}_{2}$ increases with age and maturation. The responses of the components of aerobic fitness vary in relation to age and maturation during youth. Physically active children demonstrate higher peak $\mathrm{VO}_{2}$, a faster primary time constant at the same relative exercise intensity compared with same age physically nonactive and overweight peers. Our findings are in agreement with those of Armstrong et al. (2011) and McNarry et al. (2012).

Since we did not find any research in muscle oxygenation changes among overweight or obese children and it is confirmed that NIRS significantly positively correlate with peak $\mathrm{VO}_{2}$, so we can compare our findings with those of other researchers who evaluated oxygen uptake differences among overweight children. Overweight children demonstrated the worst muscle oxygenation in all age groups compared with physically active and non-physically active children. Since ventilatory threshold could be determined by NIRS (Moalla et al., 2005) our findings are supported by Lambrick and colleagues' (2013) findings that pre-pubertal obese children during moderate and high intensity treadmill exercise demonstrated significantly worse results. During moderate intensity exercise, the phase II $\tau$, mean response time, phase II gain and oxygen deficit were significantly higher in the obese children. During high intensity exercise, the $\tau$ and phase II gains were similarly higher in the obese children.

Ratel and Blazevich (2017) state that prepubertal children were metabolically comparable to welltrained adult endurance athletes because of faster contribution of energy delivery from aerobic metabolism in working out muscle and reduced susceptibility to muscular fatigue. The results of our research support Ratel and Blazevich (2017), there were no significantly different results in muscle oxygenation among 6-10-year-old nonphysically active and 6-10-year-old physically active children, as well as among 11-15-year-old non-physically active and 11-15-year-old physically active children.

Heart rate was not significantly different among physically active, non-physically active and overweight children of 6-19-year-olds. Mean of heart rate was similar in all groups. It might be because overweight children got tired very fast, physically active children completed high intensity treadmill test, but did not reach the maximal heart rate. Our findings agree with those of Cheatham, Mahon, Brown, and Bolster (2000) who found out that responses of cardiovascular system were similar among boys (10-13 yr) and men (18-25 yr). We did not find research to confirm or deny our findings in children population, but Gayda et al. (2017) found that obese adults have a lower $\mathrm{VO}_{2}$ peak and muscle oxygenation, higher systolic blood pressure compared to non-obese peers during maximal cardiopulmonary exercise testing on ergo cycle. The reason of lower $\mathrm{VO}_{2}$ and muscle oxygenation possibly is a lower mitochondrial density/function, oxygen transport capacity and to endothelial dysfunction. These findings demonstrate risks that overweight, obesity and physical inactivity can have consequences for overweight and nonphysically children and adolescents in the future.

Time constant was significantly different among children of different age and fitness. Physically active participants demonstrated faster mean response time of muscle deoxyhemoglobin compared with physically non-active and overweight children. Our findings agree with those of Marwood, Roche, Garrard, \& Unnithan (2011), who assessed trained and untrained 15-year-old young males. Researchers found that trained subjects demonstrated faster mean response time of muscle deoxygenation compared with untrained individuals in exercise at a workload equivalent to $80 \%$ lactate threshold (trained $24.2 \pm 9.2 \mathrm{~s}$ vs. untrained $34 \pm 13 \mathrm{~s}$ ). Our findings demonstrate that in all age groups $(6-10,11-15,16-19 \mathrm{yr})$ the slowest mean response time of muscle deoxygenation was in overweight children groups. Obesity and overweight can affect respiratory system by several mechanisms: direct effect of fat in the chest wall, abdomen reduces lung volume, particularly expiratory reserve volume and causes structural changes (Brazzale, Pretto, \& Schachter, 2015).

\section{CONCUSION}

Muscle oxygenation during constant or increasing exercise is dependent on both body weight and physical activity status in 6-19- yearold children. 


\section{REFERENCES}

Armstrong N., Tomkinson, G., \& Ekelund, U. (2011). Aerobic fitness and its relationship to sport, exercise training and habitual physical activity during youth. British Journal of Sports Medicine, 45(11), 849-858. doi: 10.1136/bjsports-2011-090200

Brazzale, D. J., Pretto, J. J., \& Schachter, L. M. (2015). Optimizing respiratory function assessments to elucidate the impact of obesity on respiratory health. Respirology, 20(5), 715-21. doi: 10.1111/resp.12563

Breese, B. C., Williams, C, Barker, A. R., Welsman, J. R., Fawkner, S. G., \& Armstrong, N. (2010). Longitudinal changes in the oxygen uptake kinetic response to heavyintensity exercise in 14- to 16-year-old boys. Pediatric Exercise Science, 22, 69-80.

Cheatham, C. C., Mahon, A. D., Brown, J. D., \& Bolster, D. R. (2000). Cardiovascular responses during prolonged exercise at ventilatory threshold in boys and men. Medicine and Science in Sports and Exercise, 32(6), 1080-1087.

Dias, K.A., Masterson, C. E., Wallen, M. P., Tjonna,A.E., Hosseini, M. S., Davies, ... Coombes, J. S. (2017). Assessment of the 5-minute oxygen uptake efficiency slope in children with obesity. Pediatric Exercise Science, 29(3), 350-360. doi: 10.1123/pes.2016-0248

Dobbins, M., Husson, H., DeCorby, K., \& LaRocca, R. L. (2013). School-based physical activity programs for promoting physical activity and fitness in children and adolescents aged 6 to 18. Cochrane Database of Systematic Reviews, 28(2). doi: 10.1002/14651858. CD007651

Durbin, C., Egan, R., Gervasi, K., Nadeau, N., Neal, E., Reich, S., \& Gregory, T. (2017). The effects of obesity on pulmonary function in children. JAAPA, 30(9), 3033. doi: 10.1097/01.JAA.0000522135.76069

Ganesan, G., Leu, S., Cerussi, A., Tromberg, B., Cooper, D. M., \& Galassetti, P. (2016). Cerebral and muscle tissue oxygenation during incremental cycling in male adolescents measured by time-resolved NIRS. Pediatric Exercise Science, 28(2), 275-285. doi: 10.1123/pes.2015-0037

Gayda, M., Lapierre, G., Dupuy, O., Fraser, S., Bherer, L., Juneau, ... V, Nigam, A. (2017). Cardiovascular and cerebral hemodynamics during exercise and recovery in obese individuals as a function of their fitness status. Physiological Reports, 5(12), e13321.

Fawkner, S. G., Armstrong, N., Potter, C. R., \& Welsman, J. R. (2002). Oxygen uptake kinetics in children and adults after the onset of moderate-intensity exercise. Journal of Sports Sciences, 20, 319-326.

Ferreira, L. F., Hueber, D. M., \& Barstow, T. (2007). Effects of assuming constant optical scattering on measurements of muscle oxygenation by near-infrared spectroscopy during exercise. Journal of Applied Physiology, 102, 358368.
Harrison, F., Goodman, A., van Sluijs, E. M. F., Andersen, L. B., Cardon, G., Davey, R., ... Jones, A. P. (2017). Weather and children's physical activity: How and why do relationships vary between countries? International Journal of Behavioral Nutrition and Physical Activity, 14, 74. doi: 10.1186/s12966-0170526-7

Hebestreit, H., Kriemler, S., Hughson, R. L., \& BarOr, O. (1998). Kinetics of oxygen uptake at the onset of exercise in boys and men. Journal of Applied Physiology, 85, 1833-1841.

Lambrick, D., Faulkner, J., Westrupp, N., \& McNarry, M. (2013). The influence of body weight on the pulmonary oxygen uptake kinetics in pre-pubertal children during moderate- and heavy intensity treadmill exercise. European Journal of Applied Physiology, 113(8), 19471955. doi: 10.1007/s00421-013-2625-8

McNarry, M., Lambrick, D., Westrupp, N., \& Faulkner, J. (2015). The influence of a six-week, high-intensity games intervention on the pulmonary oxygen uptake kinetics in prepubertal, obese and normal-weight children. Applied Physiology, Nutrition, and Metabolism, 40(10), 10121018.

McNarry, M. A, Welsman, J. R., \& Jones, A. M. (2010). Influence of training and maturity status on the cardiopulmonary responses to ramp incremental cycle and upper body exercise in girls. Journal of Applied Physiology, 110. doi: 10.1152/japplphysiol.00988.2010

McNarry, M. A., Welsman, J. R., \& Jones, A. M. (2012). Influence of training status and maturity on pulmonary o2 uptake recovery kinetics following cycle and upper body exercise in girls. Pediatric Exercise Science, 24, 246-261.

Moalla, W., Dupont, G., Berthoin, S., \& Ahmaidi, S. (2005). Respiratory muscle deoxygenation and ventilatory threshold assessments using near infrared spectroscopy in children. International Journal of Sports Medicine, 26(7), 576-582. doi: 10.1055/s-2004-830332

Moalla, W., Merzouk, A., Costes, F., Tabka, Z., \& Ahmaidi, S. (2006). Muscle oxygenation and EMG activity during isometric exercise in children. Journal of Sports Sciences, 24(11), 1195-1201.

Marwood, S., Roche, D., Garrard, M., \& Unnithan, V. B. (2011). Pulmonary oxygen uptake and muscle deoxygenation kinetics during recovery in trained and untrained male adolescents. European Journal of Applied Physiology, 111(11), 2775-2284. doi: 10.1007/ s00421-011-1901-8

Okushima, D., Poole, D. C., Rossiter, X. H. R., Barstow, T. J., Kondo, N., Ohmae, E., \& Koga, S. (2015). Muscle deoxygenation in the quadriceps during ramp incremental cycling: Deep vs. superficial heterogeneity. Journal of Applied Physiology, 119, 113-119. doi: 10.1152/japplphysiol.00574.2015 
Ratel, S., \& Blazevich, A. J. (2017). Are prepubertal children metabolically comparable to well-trained adult endurance athletes? Sports Medicine, 47(8), 1477-1485. doi: 10.1007/s40279-016-0671-1.

Van Beekvelt, M. C. P., Colier, W. N. J. M., Wevers, R. A., \& Van Engelen, B. G. M. (2001). Performance of near-infrared spectroscopy in measuring local O2 consumption and blood flow in skeletal muscle. Journal of Applied Physiology, 90, 511-519.

Vandekerckhove, K., Coomans, I., Moerman, A., De Wolf, D., \& Boone, J. (2016). Characterizing cerebral and locomotor muscle oxygenation to incremental ramp exercise in healthy children: Relationship with pulmonary gas exchange. European Journal of Applied Physiology, 116(11-12), 2345-2355.
Van der Horst, K., Paw, M. J. C., Twisk, J. W. R., \& Van Mechelen, W. (2007). A brief review on correlates of physical activity and sedentariness in youth. Medicine \& Science in Sport \& Exercise, 10(7), 1241-1250. doi: 10.1249/mss.0b013e318059bf35

Willcocks, R. J., Williams, C. A., Barker, A. R., Fulford, J., \& Armstrong, N. (2010). Age- and sexrelated differences in muscle phosphocreatine and oxygenation kinetics during high-intensity exercise in adolescents and adults. NMR Biomedicine, 23(6), 569577. doi: 10.1002/nbm. 1495

Zanconato, S., Baraldi, E., Santuz, P., Rigon, F., Vido, L., Da Dalt, L., \& Zacchello, F. 1989. Gas exchange during exercise in obese children. European Journal of Pediatrics, 148(7), 614-617. 